\title{
Evaluation of energy flexibility of low-energy residential buildings connected to district heating
}

Foteinaki, Kyriaki; Li, Rongling; Péan, Thibault Q. ; Rode, Carsten; Salom, Jaume

Published in:

Energy and Buildings

Link to article, DOI:

10.1016/j.enbuild.2020.109804

Publication date:

2020

Document Version

Peer reviewed version

Link back to DTU Orbit

Citation (APA):

Foteinaki, K., Li, R., Péan, T. Q., Rode, C., \& Salom, J. (2020). Evaluation of energy flexibility of low-energy residential buildings connected to district heating. Energy and Buildings, 213, [109804].

https://doi.org/10.1016/j.enbuild.2020.109804

\section{General rights}

Copyright and moral rights for the publications made accessible in the public portal are retained by the authors and/or other copyright owners and it is a condition of accessing publications that users recognise and abide by the legal requirements associated with these rights.

- Users may download and print one copy of any publication from the public portal for the purpose of private study or research.

- You may not further distribute the material or use it for any profit-making activity or commercial gain

- You may freely distribute the URL identifying the publication in the public portal 


\section{Journal Pre-proof}

Evaluation of energy flexibility of low-energy residential buildings connected to district heating

Kyriaki Foteinaki, Rongling Li, Thibault Péan, Carsten Rode, Jaume Salom

PII:

DOI:

Reference:

To appear in:

Received date:

Revised date:

Accepted date:
S0378-7788(18)33851-9

https://doi.org/10.1016/j.enbuild.2020.109804

ENB 109804

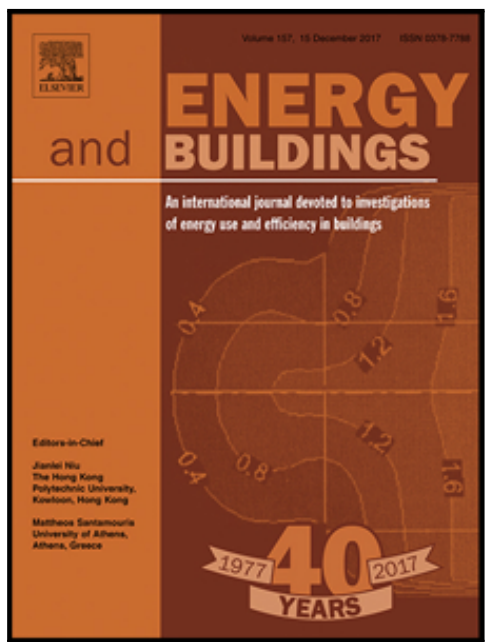

\section{Energy \& Buildings}

20 December 2018

2 November 2019

18 January 2020

Please cite this article as: Kyriaki Foteinaki, Rongling Li, Thibault Péan, Carsten Rode , Jaume Salom , Evaluation of energy flexibility of low-energy residential buildings connected to district heating, Energy \& Buildings (2020), doi: https://doi.org/10.1016/j.enbuild.2020.109804

This is a PDF file of an article that has undergone enhancements after acceptance, such as the addition of a cover page and metadata, and formatting for readability, but it is not yet the definitive version of record. This version will undergo additional copyediting, typesetting and review before it is published in its final form, but we are providing this version to give early visibility of the article. Please note that, during the production process, errors may be discovered which could affect the content, and all legal disclaimers that apply to the journal pertain.

(C) 2020 Published by Elsevier B.V. 


\section{Highlights}

- Low-energy building operated flexibly to offer services to district heating

- Dynamic heat production cost was used to control the building's heating system

- Highly effective heat load shifting was achieved to reduce peak loads

- Rule base scheduling and cost based scheduling are both effective for load shifting

- Cost reduction up to $15 \%$ was achieved under dynamic pricing 


\title{
Evaluation of energy flexibility of low-energy residential buildings connected to district heating
}

\author{
Kyriaki Foteinaki ${ }^{\mathrm{a}, *}$, Rongling $\mathrm{Li}^{\mathrm{a}}$, Thibault Péan ${ }^{\mathrm{b}, \mathrm{c}}$, Carsten Rode ${ }^{\mathrm{a}}$, Jaume Salom ${ }^{\mathrm{b}}$ \\ ${ }^{a}$ Department of Civil Engineering, Technical University of Denmark, Brovej, Building 118, 2800 Kgs. Lyngby, Denmark \\ ${ }^{\mathrm{b}}$ Catalonia Institute for Energy Research (IREC), Jardins de les Dones de Negre 1, 08930 Sant Adrià de Besòs (Barcelona), Spain \\ ${ }^{\mathrm{c}}$ Universitat Politècnica de Catalunya (UPC), C/Pau Gargallo 5, 08028 Barcelona, Spain \\ * Corresponding author, e-mail: kyfote@ byg.dtu.dk
}

\begin{abstract}
Energy flexibility is a cost-effective solution to facilitate secure operation of the energy system while integrating large share of renewables. Thermal energy infrastructure is a great asset for flexibility in systems with widely developed district heating networks. The aim of the present work is to investigate the potential for low-energy residential buildings to be operated flexibly, according to the needs of district heating system. An apartment block is studied, utilizing the storage capacity of thermal mass as storage medium. Two sets of data are utilized: heat load of Greater Copenhagen and dynamic heat production cost which is used as a price signal for the scheduling of the heating use in the building. Scenarios with different control signals are determined in order to achieve load shifting. The findings show that preheating is highly effective for load shifting and peak load reduction. During morning peak load hours, energy use is reduced in all scenarios between $40 \%$ and $87 \%$. Although with load shifting higher energy use may occur, it occurs mostly at times when the city heat load is lower and heat production is less expensive and less carbon-intensive. Indoor temperature has a wider range and/or more fluctuations, yet remains within acceptable limits.
\end{abstract}

\section{Keywords}

Energy flexibility, Building thermal mass, Heating demand, District heating

\section{Introduction}

A high penetration of renewable energy has already been achieved in many countries and it is anticipated to increase in the near future. Integrating a larger share of renewable sources in the energy system challenges the controllability and stability of the system due to the fluctuating production. The stochastic nature of the production side stresses the need for flexibility at the demand side. Methods for reducing peak loads and shifting demand have attracted great attention, 
developing the framework for appropriate markets and introducing new control strategies and end use technologies for energy storage in the system [1]. Initially, the focus was on the electricity sector, though gradually a multi-carrier energy system came into perspective, and nowadays integration of sectors is strongly encouraged. Lund et al. 2012 [2] explains the need for the electricity grids to be seen as part of integrated smart energy systems and underlines the importance of including flexible Combined Heat and Power (CHP) production for the stability of the grid. Lund et al. 2016 [3], uses an integrated cross-sector approach to identify optimum storage solutions to integrate larger shares of renewable energy, as opposed to focusing on individual sub-sectors. Münster et al. 2012 [4] underlined the importance of district heating system (DH), concluding that DH can contribute to the security of supply and sustainability of future energy systems cost-effectively.

One very important element of DH networks is the potential for short-term heat storage, facilitating the optimization of the CHP cogeneration according to the electricity sector without compromising the heating sector $[5,6]$. By use of heat storage, when there is sufficient electricity production in the system from intermittent renewable energy, for example wind turbines, CHP can decrease their production since heat can be supplied from the storage. Respectively, the CHP plant can increase the production when there is higher demand for electricity. In that case, if the heat production is higher than the heat demand, the storage can be charged; conversely, if the heat production is lower than the heat demand, the heat storage can be discharged. This provides flexibility to the energy system, which is a significant aspect for the integration of larger share of intermittent renewables, which is crucial for the optimal operation of the system both economically and environmentally. Thereby, the thermal energy infrastructure is considered a great asset for flexibility with the existing energy storage and the potential for extension.

The building sector with the already existing large mass of the building stock appears to have potential for short-term thermal energy storage. There are different possibilities for short-term thermal energy storage in the buildings, including utilization of the thermal mass of buildings, use of phase changing materials and domestic hot water storage tanks [7]. The two latter may require new investments. Although domestic hot water storage tanks are common in Danish households, especially in apartment blocks, they are not necessarily available in every building; instantaneous heat exchangers are also used to supply domestic hot water from the DH network. Phase changing materials is an emerging technology but research is still needed and applications in buildings are rare [7-9]. On the other hand, the thermal mass of the building stock is available and can be used as short-term thermal energy storage with limited investment cost for control installations. The use of the thermal mass of buildings has been studied by many researchers already and it is shown that it can be utilized as short term thermal energy storage. Most often, case study buildings connected to the electricity grid have been used, with integrated heat pumps [10-14] or with electrical space heating systems [15]. There 
are fewer studies that have worked with buildings which are connected to the district heating grid.

Compared to the electricity system, the available information and expertise on demand shifting for DH is limited. An important impediment to this is that the market structure for heat is not as developed and transparent as it is for electricity, so it is not mature yet to facilitate demand response. For instance, time-varying tariffs are not applied. Åberg et al. 2016 [16] discussed the Swedish experience: although this country has liberalized the district heating pricing the past two decades, the district heating market has not evolved yet to an integrated market. Li et al. [17] reviewed existing heat pricing models and methods and Song et al. [18] conducted a survey to capture the current structure of DH price models in Sweden, in an effort to improve DH market and heat pricing transparency. Yet, both studies [17,18] underlined that market transparency needs to be improved in order to effectively implement demand shifting strategies in the DH system. Nevertheless, important benefits are anticipated from demand response in the DH system. For the system, reduction of heat production costs by reducing the start-ups and avoiding the use of peak load boilers, handling capacity issues in the existing network, thus reducing network investment costs by more efficient use of the existing pipes and installations, running CHP plants at the most efficient states and being able to adjust the cogeneration to benefit from high potential of renewables in the electricity system, thus increasing the revenue of the CHP plant from electricity sales. In addition, environmental benefits are achieved by substituting the carbon-intensive peak load boilers and facilitating the production from renewables in the system. However, in order for the consumer to have a benefit from participating in demand response, monetary incentives need to be offered. Li et al. 2015 [17] suggests that engaging consumers on the demand side is equally important with renovating DH supply and distribution system, in order to achieve energy savings and $\mathrm{CO}_{2}$ emissions reduction and suggests the development of real-time pricing mechanism in the DH sector.

Previous work on demand response in buildings connected to DH was focused on the load shape rather than heat pricing. Wernstedt et al. [19] implemented a multi-agent system to control a DH network with 14 buildings in order to achieve peak shaving without reducing the quality of services, emphasizing the importance of taking many small local decisions to impact the overall system performance. In continuation, Johansson et al. [20] describes the results from the implementation of the load control based on the multi-agent system in three DH systems in Sweden. It was shown that the system achieved reduction of peak loads up to $20 \%$ of the total load. Basciotti and Schmidt [21] simulated an optimization algorithm, utilizing the thermal capacity of buildings with a certain flexibility in the time of reaching the set-point. The results estimated peak reduction up to $35 \%$ with about $2 \%$ increased heat use for the considered $\mathrm{DH}$ network. Dominković et al. [22] implemented an optimization model of case study energy system in a Danish city, focusing on the impact of storage in the building thermal mass on the energy supply of DH. They showed that the building thermal mass was used as intra-day storage and that it facilitated effective utilization of larger share of solar 
thermal heating energy. Evaluating the potential of individual buildings with field studies, Kensby et al. [23] presented results from 5 case studies of multifamily residential buildings, which were tested for their potential to act as thermal energy storage by adjusting the signals of the supply temperature to the radiator system, and showed that heavy concrete buildings can tolerate changes in heat deliveries without significant deterioration of indoor climate. Sweetnam et al. [24] performed a field study in 28 households connected to a DH network in England, implementing load shifting, which improved the load factor (ratio of mean to maximum demand) from 0.29 to 0.44 , with consequent increased energy use of approximately $3 \%$. To the knowledge of the authors, there are only a few studies performing demand response based on dynamic pricing. In [25] they summarized the results of three case study buildings where demand response demonstrations were carried out and propose DH tariff structures that encourage the utilization of DSM; they recommend that the tariffs in DH should reflect the suppliers' marginal heat production costs, are understandable by the customers and consider legal constraints. Deventer et al. 2011 [26] proposed and simulated an implementation of demand response, with a sensor network exchanging information between the heat supplier and the building substation. The indoor temperature set-point was modulated according to variable pricing for heating in order to reduce the energy use during peak load hours. The study showed energy use reduction of $20 \%$ while the indoor temperature was reduced by $1{ }^{\circ} \mathrm{C}$ with an outdoor temperature of $-15^{\circ} \mathrm{C}$.

\subsection{Danish district heating}

Denmark is one of the European countries with the most developed district heating networks, supplying 64\% of Danish households [27].

Figure 1 presents the percentage distribution of fuel mix for district heating production in 2016 in Denmark [28], showing that the heat generation for the Danish DH system has already integrated $52 \%$ renewable energy, principally in the form of biomass.

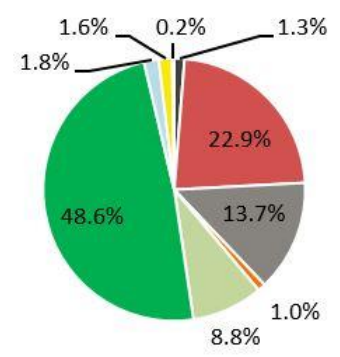

$$
\begin{aligned}
& \text { - Oil } \\
& \text { = Natural gas } \\
& \text { = Coal } \\
& \text { = Electricity } \\
& =\text { Waste (non-biodegradable) } \\
& =\text { Biomass } \\
& =\text { Biogas } \\
& =\text { Solar } \\
& =\text { Geothermal }
\end{aligned}
$$

Figure 1: Percentage distribution of fuel mix for district heating production in Denmark (2016)

According to the Danish energy targets it shall be based only on renewables by 2050. With the base load demand being gradually converted to $\mathrm{CO}_{2}$-neutral energy by using biomass-fuelled plants, heat pumps and geothermal energy, the main 
goal to be achieved is to avoid the utilization of peak load boilers, which mainly use natural gas. In addition, $69 \%$ of all heat is produced in cogeneration with electricity (CHP) [27], therefore the interaction between the sectors is profound. According to the Danish Energy Agency [29], "prudent interaction within the power and heating sector will further improve the efficiency in the energy sector and mitigate the challenges of integrating variable renewable energy sources in the power system". Extending the heat storage potential within the DH system is essential and it would further increase flexibility of the energy system.

The Danish district heating is considered a natural monopoly and it has been therefore regulated by a non-profit principle. Although the heat price paid by the consumers varies in different areas, the costs that can be included in the heating price are defined by law. According to this, the consumer pays a heat price that should cover all costs pertaining to the heat supply, as it is not permissible for the heat supply company to make profit, but they should be financially sustainable. Thereby, the heat price paid by the consumers are influenced by many parameters, including investment, operation and maintenance (O\&M) and efficiency of the production facility, investment, O\&M and heat loss in the DH network, fuel prices, taxes and VAT, subsidies, electricity price (relevant for plants that use/produce electricity) [27]. Regarding the ownership of the DH production plants, there are different structures of ownerships in Denmark. Large energy companies typically own and operate the largest plants, while smaller plants are owned by municipalities or cooperatives. Along with the non-profit principle, the structure of the cooperative provides an efficient heat supply at the lowest possible price for the end customer. The payment for heating by the customers is fixed for the whole year and it is based on private contracts between them and the respective heating supply company.

DH in Greater Copenhagen area (i.e. Copenhagen metropolitan area) is produced by different plants owned by three companies: 3 waste incineration plants and 1 geothermal plant, which are politically prioritized production, 3 CHP plants, 2 heat accumulators, 4 large peak and reserve load boilers and approximately 30 peak load units, which function as a reserve for the base load units - typically if they fail during winter. It is supplied through interconnected transmission and distribution networks. A cooperative between the DH companies has been established (Varmelast.dk). One of the main tasks of Varmelast.dk is to prepare the day-ahead heating plan, which is based on the DH forecasts disclosed by the DH companies and considers fuel prices, operating and maintenance costs, energy taxes on heat production, $\mathrm{CO}_{2}$ quota costs, income from the power market and hydraulic bottlenecks in the network [30]. Varmelast.dk performs a joint optimization of heat and power production and aims to ensure the maximum economic benefit for the entire system. The load dispatch is based on marginal heat production costs, while the heat price is defined in bilateral contracts between suppliers and buyers. The heat price contracts are confidential, i.e. not known by Varmelast.dk and define how the total benefit is shared. There are 3 scheduled intra-day adjustments of the heating plan every day with 
updated heat consumption forecasts, capacities and power prices.

The present work is part of the "EnergyLab Nordhavn - New urban energy infrastructure" project, which is a smart city research project based in the Nordhavn district, Copenhagen. Nordhavn is a new development area in Copenhagen, in which the majority of the building stock is being built from 2014 and onwards. The buildings are built according to the strict energy performance requirements of the Danish Building Regulations (BR15 [31] / BR18 [32]), thus it is defined as an area for low-energy buildings by the City of Copenhagen development plan. After economic evaluation of the available options [33], district heating was chosen for heat supply in the area. Low-energy buildings are well-insulated, airtight and may be heavy-weight with a concrete core, thus have large thermal storage capacity. To the best knowledge of the authors, this category of buildings has not been utilized yet as a potential storage medium in the DH system. A multifamily residential apartment block in Nordhavn, Denmark, is studied in the present work. The physically available thermal storage capacity existing inherently in the structural mass has been analyzed in [34] and the findings showed that low-energy buildings are highly robust and can remain autonomous for several hours. This study evaluates the feasibility of the utilization of this flexibility potential. It investigates the benefits in the DH from the exploitation of these buildings if operated flexibly. Two sets of data from the district heating system are utilized as indication for the district heating needs: the hourly heat load of Greater Copenhagen and the respective marginal heat production cost. Scenarios with different control signals are determined based on the given data, which drive the operation of the heating system of the building. The aim is to demonstrate the potential of the building for flexible operation, in order to shift heat load in time, avoiding peak load periods and utilizing heat during periods that heat production is less expensive. The implemented scenarios are evaluated based on the effect on heat production cost and load shifting potential, and the consequent energy use and thermal comfort.

The structure of this paper is organized as follows. Section 2 analyses the available data from the district heating system in Copenhagen and narrates the approach. Then, the parameters of the simulations performed are presented, including the building model and the boundary conditions. Section 3 presents and analyses the results of the simulation studies and Section 4 discusses the outcomes. The main conclusions are summarized in Section 5.

\section{Methodology}

This section explains the methodology for the evaluation of using structural thermal mass as storage medium in the DH. The charging and discharging of the storage medium, i.e. structural thermal mass, is achieved by modulating the indoor air temperature set-point. When increasing the set-point, the heat load in a building is increased and the additional heat is stored into the thermal mass. When decreasing the set-point, the heat load in a building is curtailed or interrupted, 
imposing heat to be released from the thermal mass of the building to the internal zones.

Initially in this work, a reference operation of the building was defined, with thermostatic control with constant air temperature set-point at $22^{\circ} \mathrm{C}$, which is a typical desired indoor temperature in Danish households during the heating season [35]. Then, different signals triggered an increase or decrease of the air temperature set-point in order to charge or discharge the thermal mass. At all times, thermal comfort of occupants ought not to be compromised. The limits of comfortable conditions were chosen to be between of $20-24{ }^{\circ} \mathrm{C}$, in accordance with the thermal comfort Category II "Normal level of expectations for new buildings" for heating season according to the standard EN/DS 15251[36].

\subsection{Data from district heating system}

Given the complication of the heat market in Denmark and the heat pricing mechanism, which is not transparent enough, choosing a signal to represent the needs of DH is not straightforward As previously explained, the DH price paid by the customers is based on individual contracts and is constant throughout the year, thereby, different signals had to be chosen. Two sets of data were used as indication of the district heating needs; the heat load of Greater Copenhagen and the respective marginal heat production cost. The marginal heat production cost was chosen to be used as signal, as the variation of production costs is represented and the effects of the market on the heat production are reflected adequately, as shown by Li et al.2015 [17]. Sun et al.2016 [37] showed that although the gap in magnitude between the marginal cost and the heat price is large, the marginal heat cost can adequately reflect the increase of variable heat production cost with increased heat demand. The data sets were provided to us by the DH utility company of Copenhagen, HOFOR A/S [38].

The marginal heat production cost is the cost to produce one additional unit of heat through DH. Since the DH system consists of several production plants, the marginal heat production cost of the DH system is equal to the marginal cost of the production plant with the highest operational costs. There are different factors affecting the marginal cost pricing method as reviewed by [17] and respective methods and tools developed to calculate the marginal heat cost. One of the critical factors is the allocation of joint costs of CHP plants. In Denmark, where the regulated heating supply co-exists with the liberalized electricity supply, there are two ways of allocating the costs. In small-scale CHP units, for which making profit in the electricity market is not allowed, the cost of fuel is allocated to heat and afterwards the income from selling the electricity is deducted from the total heat cost. This method has been used by Sjödin and Henning 2004 [39], after discussing different methods of allocation, and later adopted by [40] and [37]. In larger CHP plants, for which making profit in the electricity market is allowed, negotiations between the heating and electricity side define the sharing of the costs. We cannot disclose details for the calculation of the marginal heat production cost used in the present work, 
as it was performed with a tool developed and used by HOFOR A/S [38], and it is the company's confidential

information. The basic components that were included in this calculation are heat demand, fuel costs, emission taxes, variable operation and maintenance costs of the plants, income from electricity sell and subsidies. The cost was used only as a signal, instead of using heat price on demand side, to reflect the potential of savings under a dynamic pricing scheme. Figure 2 presents the hourly data for the heat load (top) and the marginal heat production cost (bottom) in Greater Copenhagen calculated for a representative year.

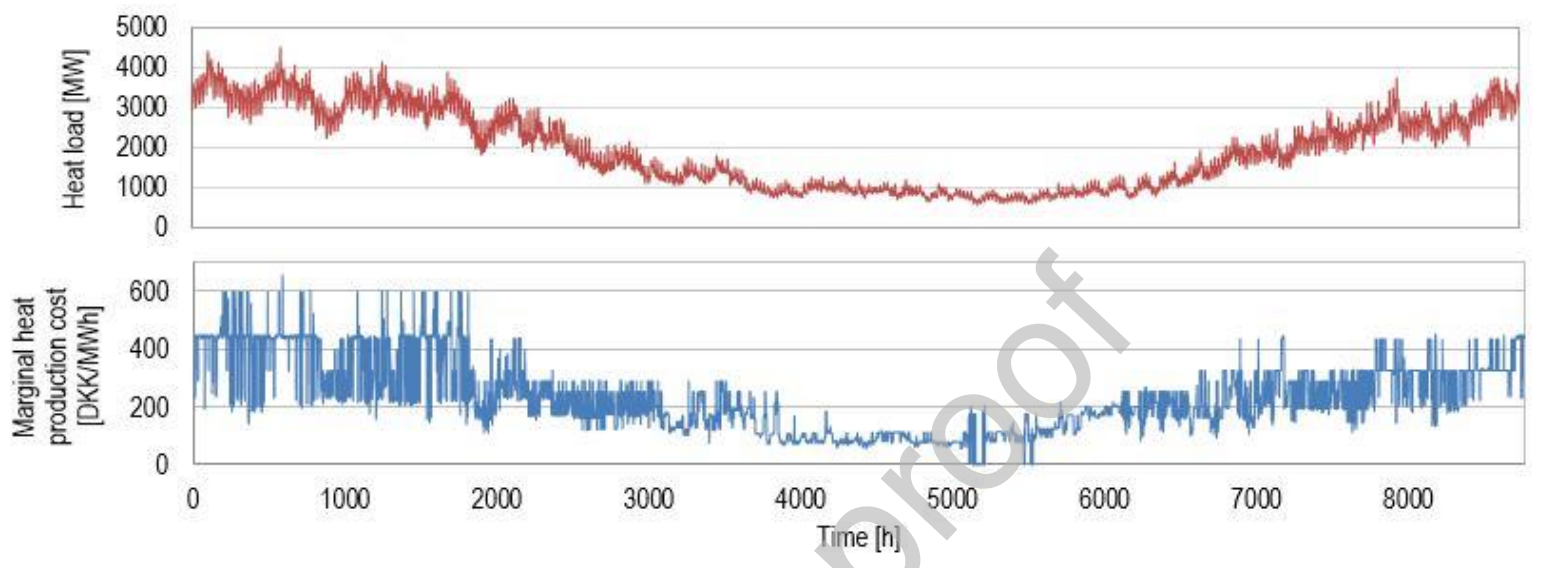

Figure 2: Hourly data for heat load (top) and marginal heat production cost (bottom) in Greater Copenhagen

The graphs show a seasonal pattern, having high heat load and high marginal heat production cost during the heating season, which both become lower in the intermediate season and lowest during summer. Analyzing the given data during the heating season, in order to identify potential patterns, Figure 3 (left) illustrates a heat map graph of the heat load, having on the x-axis the days of the heating season and on the $y$-axis the time of the day. Each time step is displayed with a small rectangle, which is colored based on the heat load value in that time step. This format shows both diurnal and seasonal patterns. In this study, heating season is the period November-March. Marginal heat production cost data are presented in the same format in Figure 3 (right).
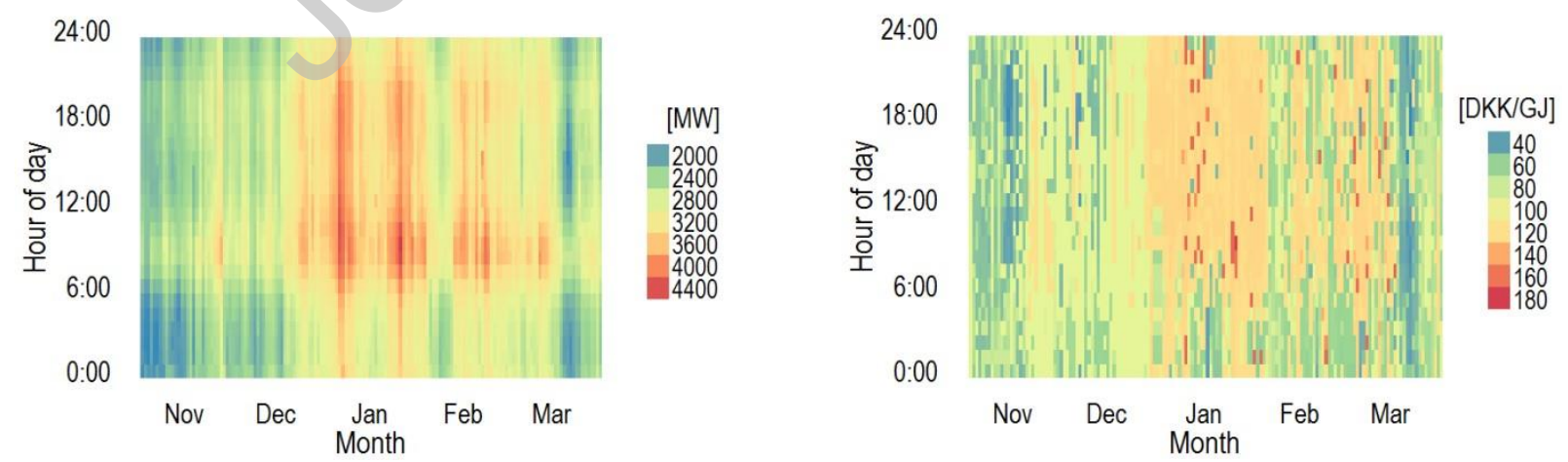

Figure 3: Heat map graph of heat load (left) and marginal heat production cost (right) in Greater Copenhagen during heating season 
The graphs indicate a correlation between the heat production cost and the heat load, but only up to a certain extent, since there are many parameters that affect the cost, as previously explained. A clear diurnal pattern of heat load can be seen. A similar pattern is observed for the marginal heat production cost, but it is not as clear as it is for heat load.

\subsection{Implementation}

There are two main different approaches to implement demand response in the building sector: direct and indirect load control [25], [41]. In the direct load control, the supplier controls directly the loads of the consumers and has the right to perform load modulations in order to facilitate the operation of the system. The indirect load control refers to ways of motivating consumers to participate in demand response, by adjusting the timing and/or the magnitude of their energy use [42]. Most often indirect control is realized based on costs; the supplier provides variable tariff schemes that will motivate the consumers to benefit from low-cost periods and avoid high-cost periods. The dynamics of the tariff scheme may vary, including time-of-year (seasonal) pricing, time-of-use pricing (daily or weekly variations), critical-peak pricing and real-time pricing. The consumers are informed about the prices one day or some hours in advance and decide whether or not to participate in this demand response activity. More demand response types can be found in literature [43], and different methods could also be combined. In our approach, indirect control was chosen assuming participation of all occupants of the examined building. Two indirect load control strategies were studied, assuming first the nonexistence and second the existence of a communication platform between the building and the supplier:

- Assuming no communication platform between the building and the heat supplier, a constant strategy was implemented with one or two flexibility events every day during the whole heating season. This could be achieved with indirect control by giving monetary incentives to the occupants, for example fixed contract with time-of-use tariffs. The occupants set lower temperatures when the heat cost is high and vice versa. In this case, fixed schedules for temperature set-points were used (Section 2.2.1), determined based on average daily profiles of the heat load of the area and the marginal heat production cost.

- Assuming a communication platform between the building and the heat supplier, a signal is sent to the building from the supplier to communicate the need for load adjustment and the home management system modulates the temperature set-points according to this signal. In this case, the signal was the hourly marginal heat production cost (Section 2.2.2).

\subsubsection{Fixed schedules for temperature set-points}

Based on the average daily profiles of heat load and marginal heat production cost, it is, on average, favorable for the system to utilize heat during night time, in order both to flatten the heat load curve of Greater Copenhagen and to use 
heat with lower production cost. Figure 4 shows scenarios with scheduled temperature set-points. Scenario 1 allowed for lower indoor temperature during the day. Scenario 2 was more conservative in terms of thermal comfort, with the setpoint being lower for shorter period, i.e. in the morning and afternoon. Scenario 3 had the same pattern as Scenario 1, but with higher temperature during night, in order to pre-heat the building before the lower temperature set-point period starts. Scenario 4 was similar to scenario 2, but with night pre-heating of the building. Two sets of modulations were performed, one with temperature range $21-23^{\circ} \mathrm{C}$ and another one with $20-24{ }^{\circ} \mathrm{C}$, in order to evaluate the potential with different ranges of thermal comfort. These scenarios were opposite from typical night setback. Night setback increases morning peak load, while in this study we aim to reduce the morning and evening peak loads

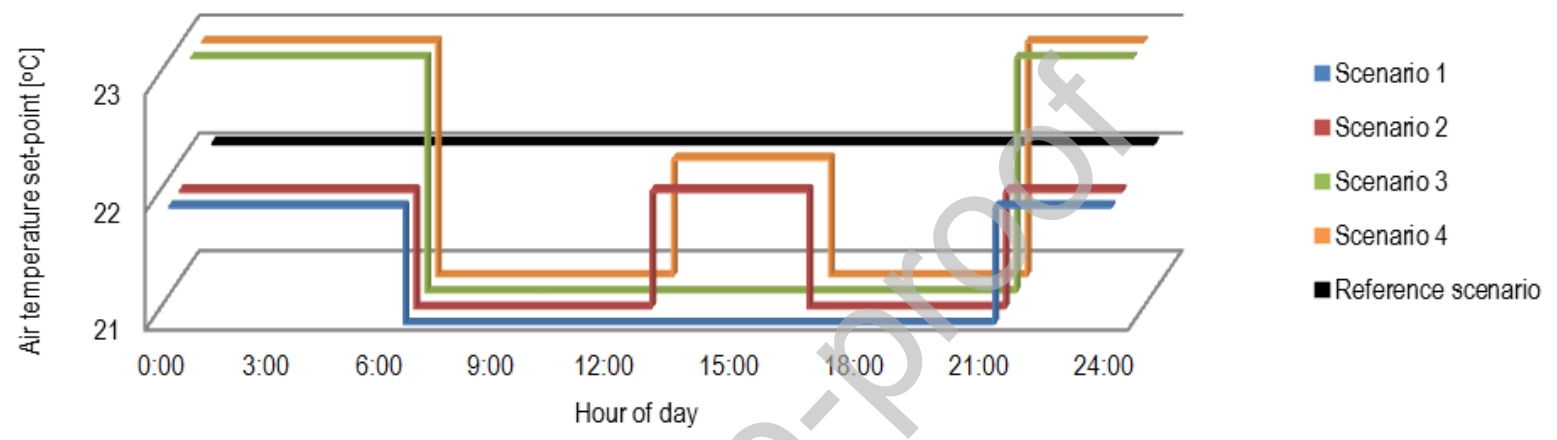

Figure 4: Scenarios for fixed schedules for temperature set-points with temperature range $21-23{ }^{\circ} \mathrm{C}$

\subsubsection{Dynamic temperature set-points}

The aim of this strategy was to shift the energy use towards the hours when heat costs are low. Therefore, thresholds for the marginal heat production costs were set, according to which the building modulates the temperature set-points. When the signal was lower than the low cost threshold $\left(\mathrm{C}_{\text {low }}\right)$, the set-point was increased, in order to store heat in the thermal mass of the building. Likewise, when the signal was higher than the high cost threshold $\left(\mathrm{C}_{\text {high }}\right)$, the set-point was decreased to discharge the stored heat. When the signal was between the two thresholds, an interpolation for the set-point was used given in Eq. 1. In addition, a deadband of $0.5^{\circ} \mathrm{C}$ was used to prevent the controller from activating for small temperature deviations.

$$
\mathrm{T}_{\text {setpoint }, \mathrm{i}}= \begin{cases}\mathrm{T}_{\text {setpoint,min }}, & \mathrm{C}_{\mathrm{i}}>\mathrm{C}_{\text {high }} \\ \mathrm{T}_{\text {setpoint,max }}, & \mathrm{C}_{\mathrm{i}}<\mathrm{C}_{\text {low }} \\ \frac{\mathrm{T}_{\text {setpoint,max }}-\mathrm{T}_{\text {setpoint,min }}}{\mathrm{C}_{\text {high }}-\mathrm{C}_{\text {low }}} \cdot\left(\mathrm{C}_{\text {high }}-\mathrm{C}_{\mathrm{i}}\right)+\mathrm{T}_{\text {setpoint,min }}, & \mathrm{C}_{\text {high }} \geq \mathrm{C}_{\mathrm{i}} \geq \mathrm{C}_{\text {low }}\end{cases}
$$

The marginal heat production cost has large seasonal variations and significant differences between the months of the heating season [17]. In the present work, the percentile distribution of marginal cost for each month was used and the thresholds referred to the respective percentiles of each month individually. Similar to the previous strategy, scenarios without and with pre-heating of the building were studied. 
Table 1 presents the scenarios examined with the minimum and maximum temperature set-point for each scenario, as well as low and high cost thresholds defined as percentiles of the monthly marginal cost. For scenarios without preheating (Scenarios 5-6), $\mathrm{C}_{\text {low }}$ was not needed, since the set-point was either decreased or maintained. In scenarios with different thresholds, the $25 \%$ or $50 \%$ percentile of the monthly cost distribution were used as $\mathrm{C}_{\text {low }}$, and the $50 \%$ or $75 \%$ percentile of the monthly cost distribution were used as $\mathrm{C}_{\text {high }}$ (Scenarios 7-10). The temperature range used in these scenarios is $21-23^{\circ} \mathrm{C}$, since the set-points were generally modulated more times per day than these of the fixed schedules, so $\pm 2{ }^{\circ} \mathrm{C}$ was not considered appropriate.

Table 1: Scenarios for dynamic modulations for temperature set-points with the respective cost thresholds

\begin{tabular}{llllll}
\hline & $\mathbf{T}_{\text {setpoint, } \min }$ & $\mathbf{T}_{\text {setpoint, } \max }$ & $\mathbf{C}_{\text {low }}$ & $\mathbf{C}_{\text {high }}$ \\
\hline Scenario 5 & No pre-heating & $21^{\circ} \mathrm{C}$ & $22^{\circ} \mathrm{C}$ & - & $50 \%$ \\
Scenario 6 & No pre-heating & $21^{\circ} \mathrm{C}$ & $22^{\circ} \mathrm{C}$ & - & $75 \%$ \\
Scenario 7 & Pre-heating & $21^{\circ} \mathrm{C}$ & $23^{\circ} \mathrm{C}$ & $25 \%$ & $75 \%$ \\
Scenario 8 & Pre-heating & $21^{\circ} \mathrm{C}$ & $23^{\circ} \mathrm{C}$ & $50 \%$ & $75 \%$ \\
Scenario 9 & Pre-heating & $21^{\circ} \mathrm{C}$ & $23^{\circ} \mathrm{C}$ & $25 \%$ & $50 \%$ \\
Scenario 10 & Pre-heating & $21^{\circ} \mathrm{C}$ & $23^{\circ} \mathrm{C}$ & $50 \%$ & $50 \%$ \\
\hline
\end{tabular}

\subsubsection{Performance evaluation}

For the scenarios examined, the following parameters were evaluated.

i. The total energy used for space heating of the building for the whole heating season, given by Equation (1):

where: $E_{i}$, the space heating energy use for every hour.

$$
E_{\text {tot }}=\sum_{1}^{\text {heating season }} E_{i}
$$

ii. The total production cost of the heat that was used in the building for space heating. It is given by Equation (2):

where: $M H P C_{i}$, the marginal heat production cost of every hour.

$$
M H P C_{\text {tot }}=\sum_{1}^{\text {heating season }} E_{i} \cdot M H P C_{i}
$$

iii. The indoor operative temperature, as an indicator of thermal comfort [36]. For the sake of clarity, the operative temperature of the critical apartment is presented, which is a top-corner apartment and was chosen because of its higher exposure to ambient conditions.

iv. The energy used for space heating of the building between 6:00-9:00, namely the morning peak load hours [44].

v. The potential for flexible operation, based on two flexibility indicators, equivalent to the one defined in [45]:

a) Evaluation of total energy use during high load hours versus during low load hours according to Equation (3):

$$
F_{1}=\frac{E_{\text {low load }}-E_{\text {high load }}}{E_{\text {low load }}+E_{\text {high load }}}
$$

where: $E_{\text {high load }}$, the total space heating energy use during high load hours, between 6:00-21:00,

$E_{\text {low load }}$, the total space heating energy used during low load hours, between 21:00-6:00 (next morning). The 
indicator ranges between -1 and 1 , with the optimal operation being when $F_{1}=1$, namely energy was used only during low load hours.

b) Evaluation of total energy use during high production cost hours versus during low production cost hours, according to Equation (4):

$$
F_{2}=\frac{E_{\text {low cost }}-E_{\text {high cost }}}{E_{\text {low cost }}+E_{\text {high cost }}}
$$

where: $E_{\text {high cost }}$, the total space heating energy use during high production cost hours, when the cost was higher than the median value of costs of each month, $E_{\text {low cost }}$, the total space heating energy use during low production cost hours, when the cost was lower than the median value of costs of each month. The indicator ranges between -1 and 1 , with the optimal operation being when $F_{2}=1$, namely energy is used only during low production cost hours.

The scenarios were implemented for the entire heating season and were evaluated based on parameters $i$, ii and iii. A selection of the implemented scenarios was further evaluated using average load and temperature profiles and parameters $i v$ and $v$. Evaluation of the scenarios was also performed for a cold day in Denmark with average ambient temperature of $-8^{\circ} \mathrm{C}$ and daily solar irradiance of $2.2 \mathrm{kWh} / \mathrm{m}^{2} /$ day.

\subsection{Building model}

The building type studied was a multifamily apartment block (Figure 5), designed according to the Danish Building Regulation 2015 (BR15) [31]. It represents a typical Danish building of this type, it is heavy-weight and well insulated, as according to BR15, "the total demand of the building for energy supply for heating, ventilation, cooling and domestic hot water must not exceed $30.0 \mathrm{kWh} / \mathrm{m}^{2}$ per year plus $1000 \mathrm{kWh}$ per year divided by the heated floor area". The design, construction and materials chosen were in accordance with BR15 and Danish Building Research Institute (SBi) Guidelines ‘Energy Demand for Buildings’ [46]. Some details were supplemented by TABULA Webtool [47].

\section{Figure 5: Apartment block model}

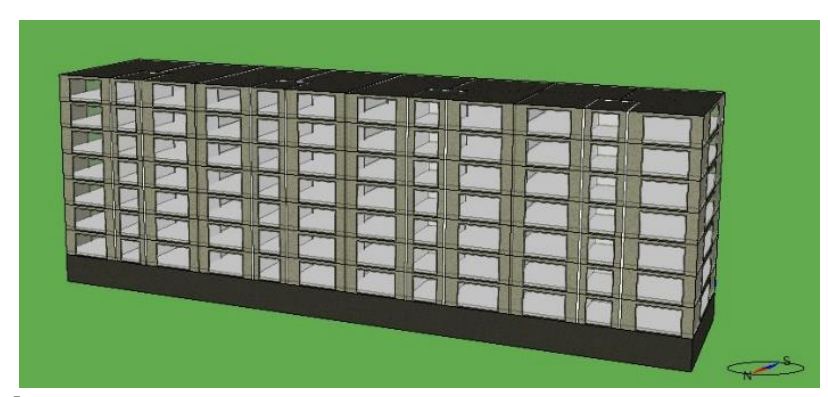

The building has a net heated floor area of $6272 \mathrm{~m}^{2}$ and envelope area per volume $0.265 \mathrm{~m}^{2} / \mathrm{m}^{3}$. It consists of 7 floors and an unheated basement. Each floor has 8 apartments with the same floor area of $112 \mathrm{~m}^{2}$ each, and 4 staircases with the same floor area of $21 \mathrm{~m}^{2}$ each. The windows comprise $22.5 \%$ of the heated floor area and are distributed $52 \%$ south, $37 \%$ 
north and $11 \%$ east/west. The apartment block is modelled as one thermal zone per apartment and one thermal zone per staircase, using adequate zone multiplication of the zones that present similar thermal behavior. The building is connected to the DH grid. In this study only space heating was investigated, as the objective of the work was to evaluate the storage of the building structure itself. The heat emission system is low temperature water radiators of maximum heating power $14 \mathrm{~W} / \mathrm{m}^{2}$ heated floor area and the supply water temperature is $45^{\circ} \mathrm{C}$. There is mechanical ventilation in the building with constant air volume of $0.3 \mathrm{l} / \mathrm{s}$ per $\mathrm{m}^{2}$ of heated floor area with heat recovery of $67 \%$ efficiency ${ }^{1}$, according to BR15. Detailed information of the building model can be found in [34]. The simulations were performed with the building performance simulation software IDA Indoor Climate and Energy, version 4.7 [48]. It is a dynamic whole-building simulation tool based on symbolic equations stated in Neutral Modeling Format (NMF) that has undergone validation tests [49-52]. The building, systems, controls, network airflow, etc. are simulated in an integrated way and the time-step varies dynamically during runtime to automatically adapt to the nature of the problem.

\subsubsection{Boundary conditions}

The boundary conditions contribute significantly to the performance of structural thermal mass as storage medium. The ambient weather conditions used in this study were weather data collected from the DTU Climate Station [53] for the year corresponding to the heat load and marginal heat production cost data. Figure 6 presents indicatively the ambient air temperature and global solar irradiance.

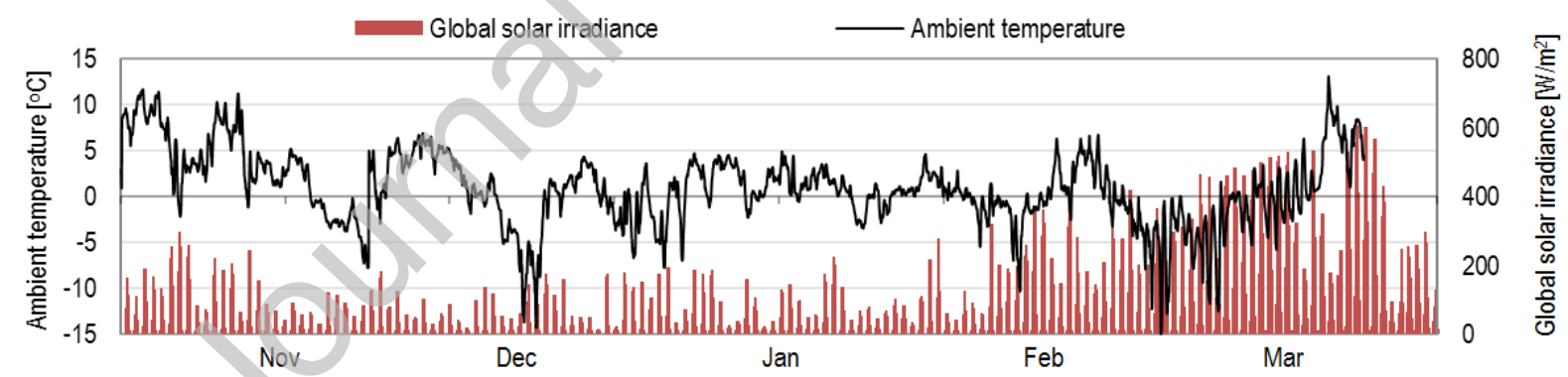

Figure 6: Ambient air temperature and global solar irradiance for the heating season

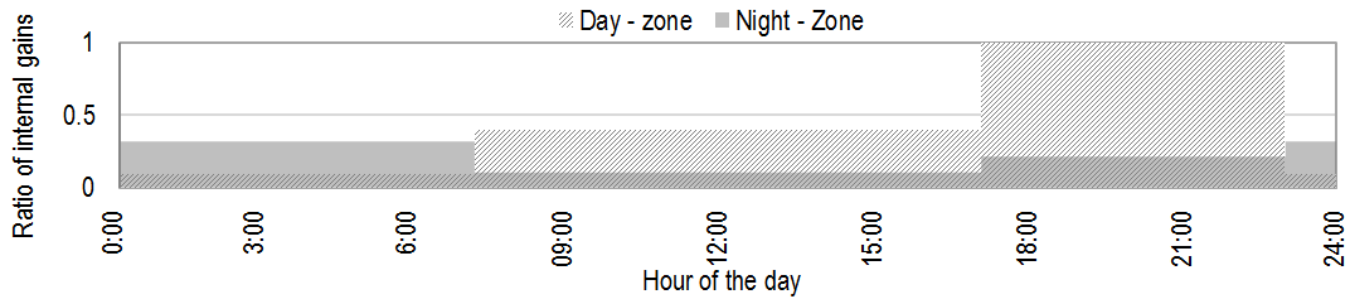

Figure 7: Schedules for internal gains according to DS/EN ISO 13790:2008

\footnotetext{
${ }^{1}$ When this study was finished, the new building regulation 2018 (BR18) was published. The only difference in the new regulation is the efficiency of heat recovery of the ventilation system for apartment blocks, which, in the new code, is $80 \%$. If the simulations were run according to BR 18 , the only difference in the results would be the heating demand for the apartment block, which would slightly decrease.
} 
The internal heat gains included heat emitted from lighting, equipment and occupants. The schedules for the internal gains were set according to the standard DS/EN ISO 13790:2008 Table G.8 [54], which were different for primarily day or night occupied zones. Since in the model there was one thermal zone per apartment, two components of internal gains were used in the same zone, one for each schedule. Figure 7 shows the ratio of internal gains compared to the maximum internal gains for every hour of the day. The total heat flow rate from internal gains was $5 \mathrm{~W} / \mathrm{m}^{2}$, which was lower than the one indicated by the standard [54], but it was adjusted in order to meet the average Danish national values [46].

\section{Results}

During the reference operation of the building, namely when the building was controlled with constant temperature set-point at $22^{\circ} \mathrm{C}$, the energy use for space heating was $12 \mathrm{kWh} /\left(\right.$ year $\cdot \mathrm{m}^{2}$ net heated floor area) and the peak demand was $82 \mathrm{~kW}\left(13.1 \mathrm{~W} / \mathrm{m}^{2}\right)$. Details on the energy performance, the thermal behavior and the physically available energy flexibility of this building can be found in [34].

This section presents the results of the flexibility potential when the building was operated during the entire heating season. Firstly, an example of the control operation is presented for one week of February, in order to demonstrate the operation of the two different strategies implemented, namely fixed set-point modulations (e.g. Scenario 3) and dynamic set-point modulations reacting to the signal (e.g. Scenario 9). Figure 8 (top) depicts the heat load of Greater Copenhagen and Figure 8 (middle) the marginal heat production cost, as well as $\mathrm{C}_{\text {low }}$ and $\mathrm{C}_{\text {high }}$ for Scenario 9. Figure 8 (bottom) shows the respective set-points according to Scenario 3 and Scenario 9.

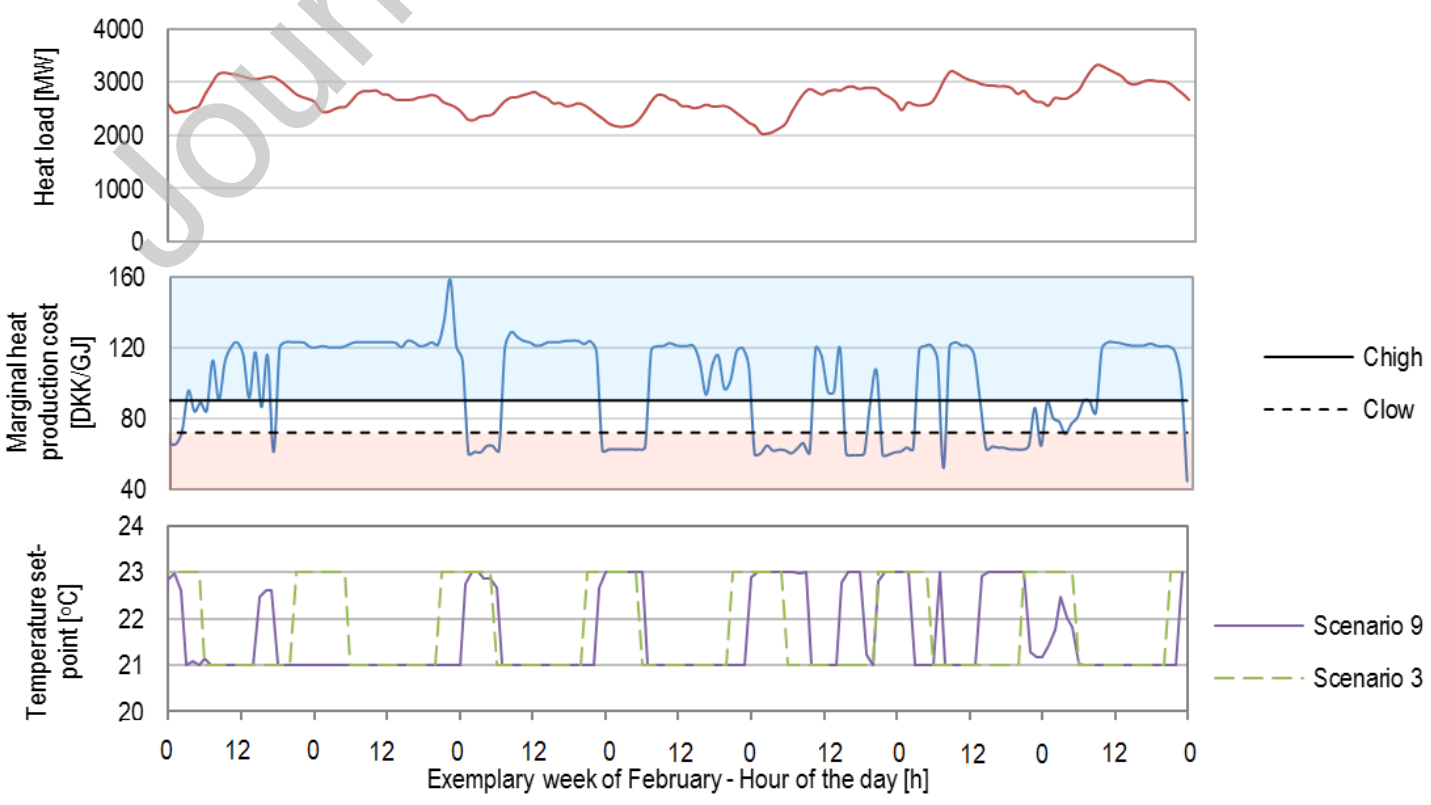

Figure 8: Exemplary week of February. Top: Heat load in Greater Copenhagen., Middle: Marginal heat production cost, $\mathbf{C}_{\text {high }}$ and $C_{\text {low }}$ for Scenario 9. Bottom: Temperature set-points according to Scenario 3 and Scenario 9 
In Scenario 3, the set-point was modulated at fixed hours, thereby it roughly followed inversely the heat load pattern by increasing the demand at night, when the heat load on the district heating system is usually lower. Scenario 9 reacted inversely to the cost signal, aiming to utilize heat when it costs less to be produced. There was a correlation in the patterns of the marginal heat production cost and the heat load, which was reflected in the operation of the control setpoints of Scenarios 3 and 9, but only to a certain extent. For instance, in this exemplary week, during the second day the set-point of Scenario 9 remained unaltered, while in the fifth and sixth day it was modulated more often than that of Scenario 3 .

\subsection{Effects of fixed schedules for temperature set-points}

This subsection presents the results for the scenarios that control the temperature with fixed set-point schedules. Figure 9 presents the difference between the reference operation of the building and each scenario examined. The top figure shows the cost of heat used in the building during the heating season, while the middle figure shows the total energy use during the heating season. The bottom figure shows box plots of the operative temperature in the critical apartment across the heating season, for the reference operation and the scenarios examined.
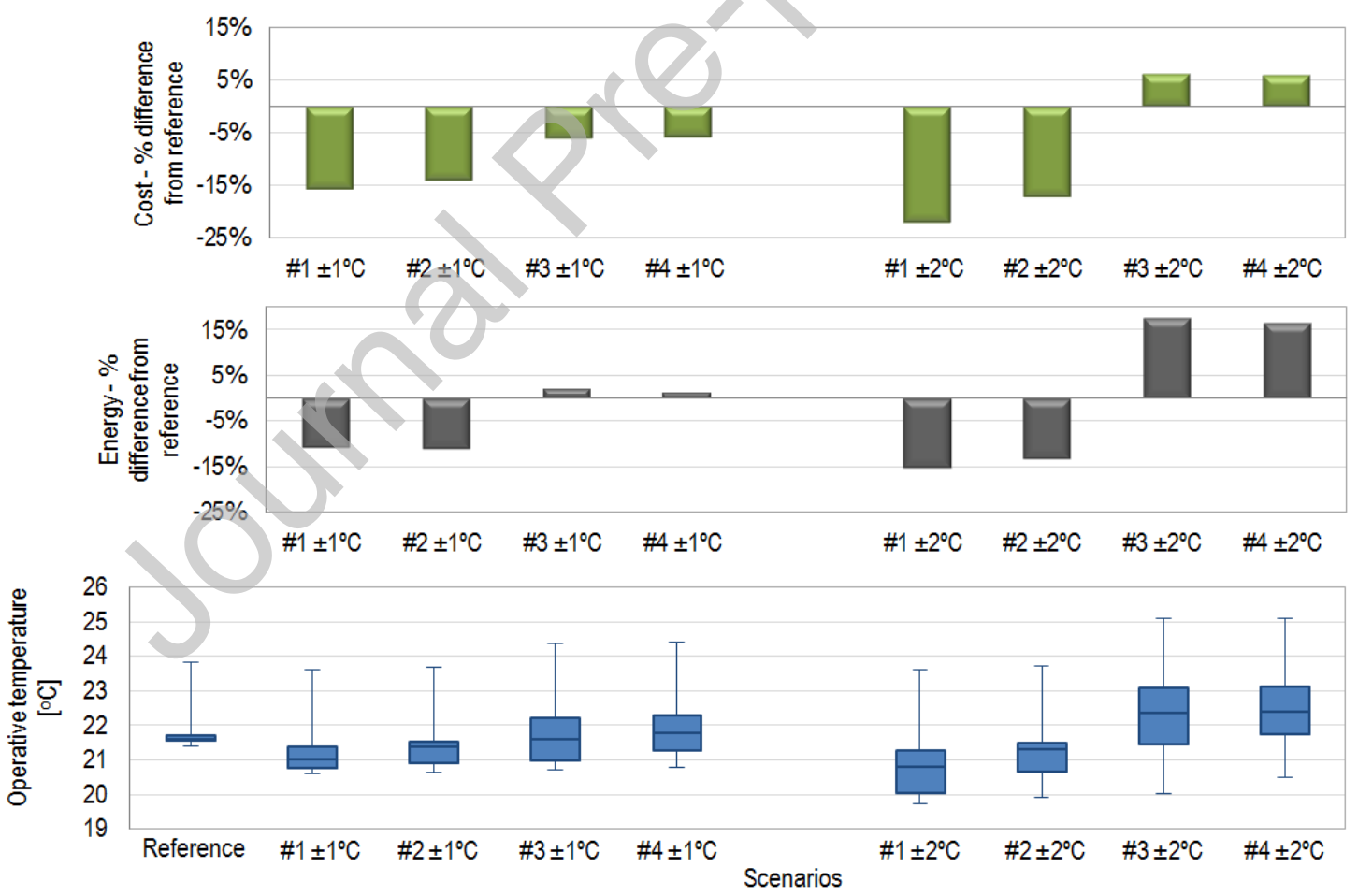

Figure 9: Effects of fixed schedules. Top: Percentage difference of cost between the reference operation and each scenario. Middle: Percentage difference of energy use between the reference operation and each scenario. Bottom: Box plots of operative temperature in the critical apartment during the heating season for the reference operation and each scenario.

For Scenarios 1 and 2, using the $\pm 1^{\circ} \mathrm{C}$ modulation schemes, the cost was lower by $15.5 \%$ and $14 \%$ respectively for the two scenarios compared to the reference operation of the building, while the total energy use was lower by $11 \%$. This difference is attributed to the lower operative temperatures throughout the heating season. The mean value of the 
operative temperatures was lower by $0.6^{\circ} \mathrm{C}$ for Scenario 1 and by $0.3{ }^{\circ} \mathrm{C}$ for Scenario 2 . Scenarios 3 and 4 , which preheat the building during the night, presented a different behavior. The cost was decreased by $6 \%$, while the total energy use was marginally increased by $2 \%$ and $1.5 \%$, respectively. The mean operative temperature was almost the same as in the reference operation, but temperature was fluctuating within a wider range. Thereby, although using marginally higher energy, the cost was decreased with small thermal comfort variations.

When the same schedules were implemented but with $\pm 2{ }^{\circ} \mathrm{C}$, the differences were apparent. For the two scenarios without pre-heating of the building, both the cost and the energy use decrease were higher, but at the expense of lower operative temperatures, which dropped below $20^{\circ} \mathrm{C}$. For the scenarios with pre-heating of the building during the night, there was higher cost and total energy use compared to the reference operation, which is attributed to the overall higher operative temperatures. Furthermore, the temperature fluctuations were strong, which in many cases are associated with thermal discomfort. Therefore, those strategies with set-point modulations of $\pm 2{ }^{\circ} \mathrm{C}$ are not recommended for a control strategy of daily fixed schedules throughout the heating season in a low-energy building, but they can be possibly used for occasional events with other control strategies.

\subsection{Effects of dynamic temperature set-points}

This subsection presents the results for the scenarios that control the temperature according to the signal of marginal heat production cost. Figure 10 presents the difference between the reference operation of the building and each scenario examined. The top figure shows the cost of heat used in the building during the heating season, while the middle figure shows the total energy use during the heating season. The bottom figure shows box plots of the operative temperature in the critical apartment across the heating season, for the reference operation and the scenarios examined. 


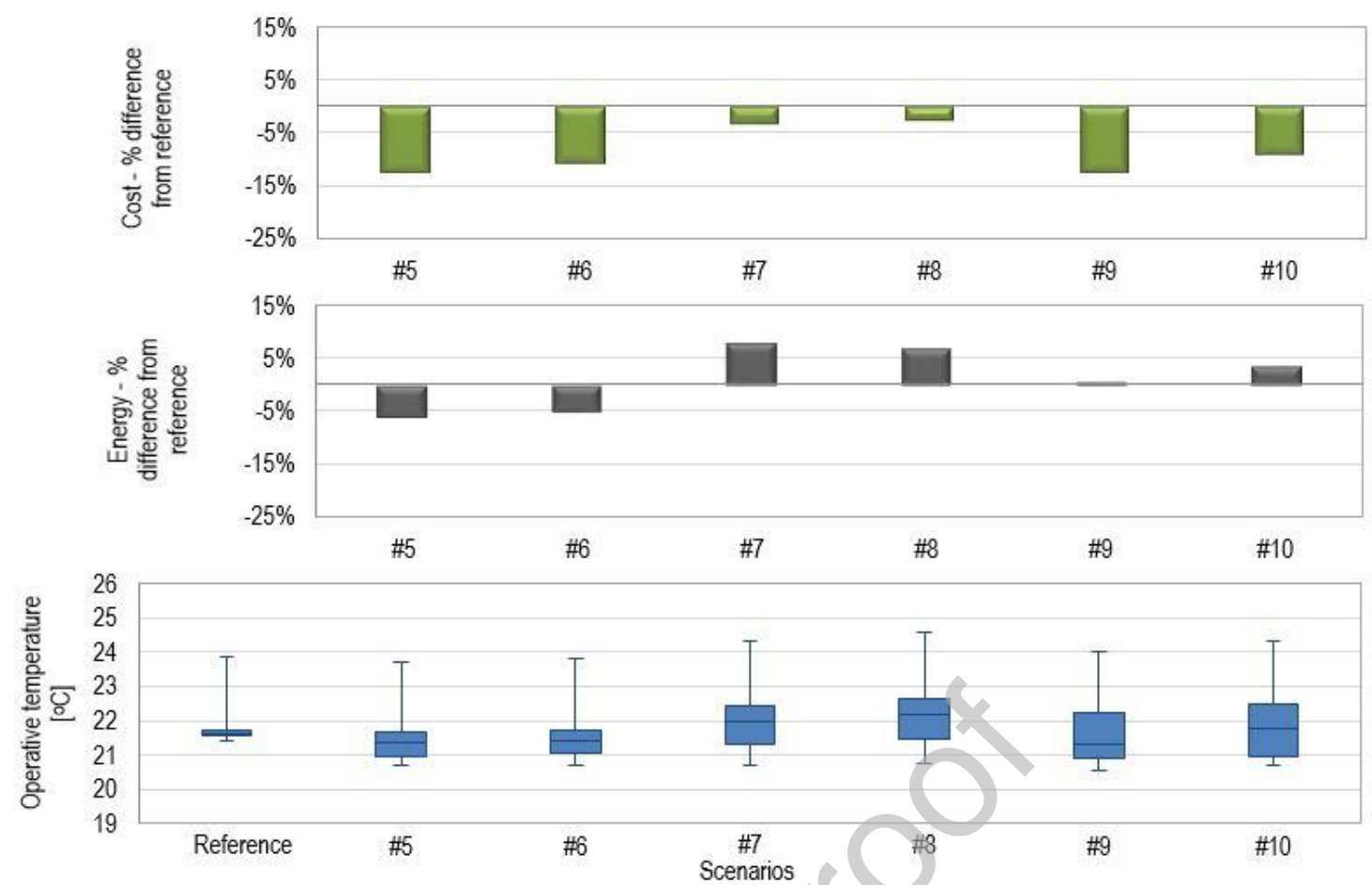

Figure 10: Effects of dynamic signal. Top: Percentage difference of cost between the reference operation and each scenario. Middle: Percentage difference of energy use between the reference operation and each scenario. Bottom: Box plots of operative temperature in the critical apartment during the heating season for the reference operation and each scenario.

All scenarios implemented achieved cost reduction between $3 \%$ and $12 \%$, while the effect on energy use and operative temperatures varied among the different scenarios. Scenarios 5 and 6, which allowed only decrease of temperature setpoint, not increase, behaved similarly to Scenarios 1 and 2 , but the effects were at a slightly lower magnitude. In Scenarios 5 and 6 cost was reduced by $12 \%$ and $11 \%$, and energy by $6 \%$ and $5 \%$. The median temperature was lower by $0.3^{\circ} \mathrm{C}$ and $0.2^{\circ} \mathrm{C}$ respectively, while there were marginally wider temperature ranges. Scenarios 7 and 8 set the high cost threshold higher than the other scenarios, so the temperature set-point is decreased less often. As a result, overall higher temperatures occurred compared to the other dynamic scenarios and the reference operation; thereby, higher total energy was used. Although cost was still decreased, the magnitude of the decrease was lower than any other dynamic scenario. Scenario 9 set the low cost threshold at the $25 \%$ percentile, so the temperature set-point was increased less often. There was a significant decrease of cost by $12 \%$, while the energy use was almost the same as the reference operation. The mean operative temperature was moderately lower and the temperature fluctuated within a wider range. Scenario 10 set both the high and the low thresholds approximately at the median value of the costs, such that the temperature set-point is frequently modulated. This led to a wide temperature range and higher energy use by $3.5 \%$. Nevertheless, the costs were still lower by $9 \%$.

From the results presented so far it is not clear which is the best performing scenario. Some scenarios indicated higher potential for cost reduction, which resulted in changes in the total energy use and indoor temperatures. The choice would 
depend on the services that the building is to offer to the district heating system considering also the thermal comfort required by occupants. In the following section further analysis is performed on the effects of some of the scenarios.

\subsection{New heating profiles and energy flexibility}

Based on the evaluation of the performance of scenarios so far, half of the scenarios were selected, in order to further investigate the effects of their implementation. Scenarios 1-4, which modulate the temperature by $\pm 1^{\circ} \mathrm{C}$, were selected for the fixed schedules. From the scenarios with dynamic signals, Scenarios 5, 6 and 9 were selected, since higher cost decrease was achieved. The average daily heat load patterns were calculated for the different scenarios and are depicted in Figure 11 (left), together with that of Greater Copenhagen (right axis). Figure 11 (right) presents the average daily profile of indoor temperatures in the different scenarios and the reference operation.
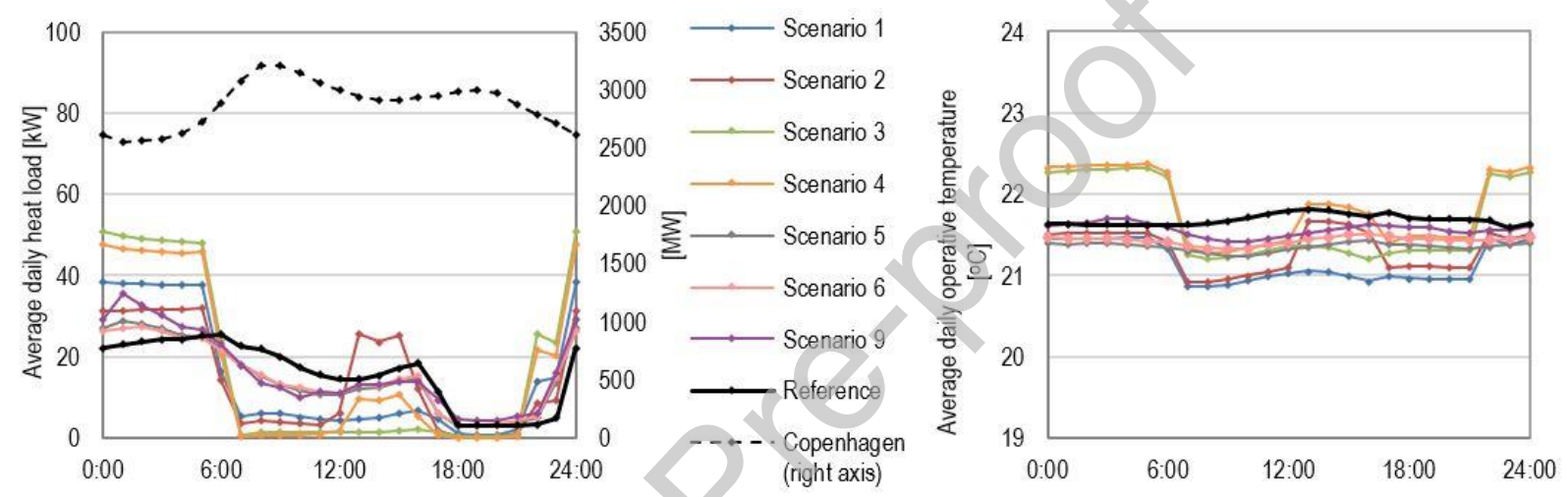

Figure 11: Left: Average daily heat load of the building in different scenarios and reference operation (left axis); average daily heat load in Greater Copenhagen (right axis). Right: Average daily operative temperature in different scenarios and reference operation

For all scenarios implemented, the maximum load was increased compared to the reference operation. The scenarios with pre-heating of the building presented higher peak loads, which was expected since the temperature increase that needed to be achieved, i.e. from $21{ }^{\circ} \mathrm{C}$ to $23^{\circ} \mathrm{C}$, was higher, hence the peak load was higher. The scenarios which only decreased the set-point presented a behavior closer to that of the reference operation. The occurrence of new peak loads was a result that was anticipated, but it is under discussion whether it undermines the implementation of those strategies. In terms of the building itself, the new peaks were within the installed capacity of the heating system, so no additional investment would be required. Therefore, technically for the building it is not problematic. Regarding the DH system, the time when the new peaks occur is essential. For all scenarios the highest heating use occurred during the night period, i.e. 21:00 -6:00, with new peaks been created at the transition between the day set-point to the night set-point. This means that the new peaks occurred at hours when the overall load of the system is low, and on average the marginal heat production cost is low. Thereby, the new peaks may not pose challenges to the system; however this would depend on the scale of the implementation. In all cases, load shifting from day to night was achieved, so the daily load pattern of the 
building acted towards smoothing the load of the Greater Copenhagen, which was indeed one of the targets.

The morning peak in the heat load of Greater Copenhagen which occurs between 6:00-9:00 could be mitigated by lowering the space heating demand in this type of buildings during this period. All scenarios examined had lower energy use during this period, but the scenarios with fixed schedules for set-points achieved higher reductions. The highest reductions in the morning energy use were achieved in Scenarios 4 and 3 by $86.5 \%$ and $83 \%$ respectively. For the scenarios with dynamic response to the cost signal the reductions were around $41 \%$. The evening peak in the heat load of Greater Copenhagen, which occurs around 19:00, cannot be mitigated with these scenarios in this type of buildings, since the space heating demand for the reference operation was already minimal due to the internal heat gains during these hours.

Regarding the average daily profile of indoor temperatures, the scenarios with the fixed temperature schedules presented a clear pattern, with Scenarios 1 and 2 being constantly below the temperatures of the reference operation, while Scenarios 3 and 4 fluctuated higher and lower than those of the reference. In scenarios with dynamic signals the average daily pattern appeared to be smooth, with small fluctuations during the day. Although in Figure 10 it was shown that the indoor temperatures in these scenarios covered a broader spectrum of temperatures, when they were averaged on a daily basis they levelled out to smooth profiles.

Figure 12 presents the performance of the implemented scenarios according to the two flexibility indicators described in Section 2.2.3. Flexibility indicator $F_{l}$ (blue bars), evaluates the total energy use during high load versus low load hours. The optimal operation is when the flexibility indicator is equal to 1 , namely energy is used only during low load hours. Flexibility indicator $F_{2}$ (green bars), evaluates the total energy use during high production cost versus low production cost hours. The optimal operation is when the flexibility indicator is equal to is 1, namely energy is used only during low production cost hours.

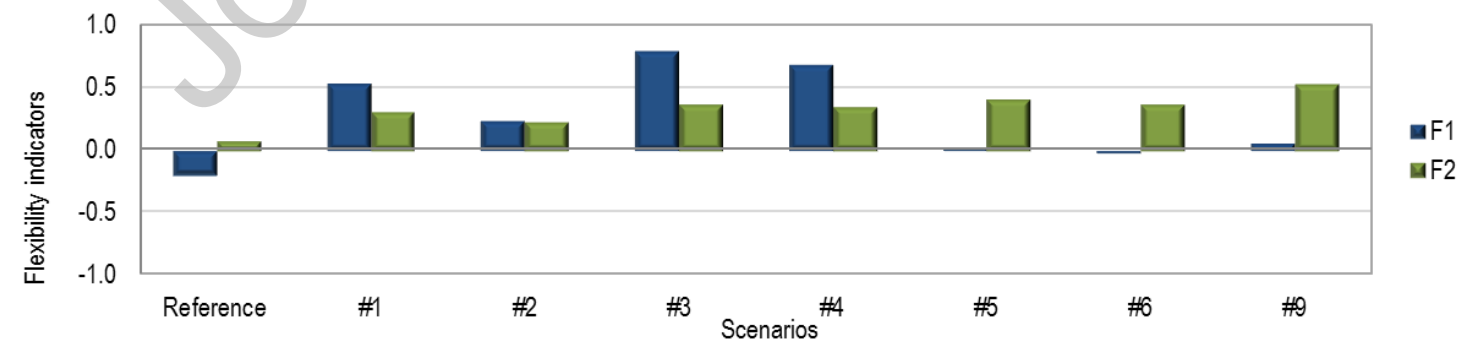

Figure 12: Flexibility indicators in different scenarios and reference operation

It can be seen that for all scenarios, both indicators improved compared to the reference operation of the building. $F_{l}$ for the reference operation was -0.20 , namely there was higher energy use during the high load hours than during low load hours. The scenarios with fixed schedules for set-points achieved higher values for $F_{l}$. The highest value of $F_{l}$ was achieved for Scenario 3 (0.79) followed by Scenario 4 (0.67), which were the scenarios with pre-heating during night. 
The scenarios with dynamic response to the cost signal, improved the indicator compared to the reference operation, but only to a lower degree. Regarding $F_{2}$, during reference operation of the building it was almost 0 , which means that there was equal energy use during high and low production cost period. The scenarios with dynamic response to the cost signal achieved higher values, with Scenario 9 being the highest with 0.52 .

Table 2 shows the average performance and flexibility potential from the implementation of the selected scenarios.

Table 2: Average performance and flexibility potential in different scenarios during the heating season

\begin{tabular}{llllll}
\hline & \multicolumn{5}{c}{ Difference from reference operation } \\
\cline { 2 - 5 } Scenarios & Cost [\%] & $\begin{array}{l}\text { Energy use in } \\
\text { morning [\%] }\end{array}$ & $\begin{array}{l}\text { Average } \\
\left.\text { temperature [ }{ }^{\mathbf{0}} \mathbf{C}\right]\end{array}$ & Total energy [\%] & F1 \\
\hline Reference & - & - & - & - & -0.20 \\
Scenario 1 & $-15.5 \%$ & $-74.0 \%$ & -0.6 & $-10.8 \%$ & 0.53 \\
Scenario 2 & $-14.0 \%$ & $-80.6 \%$ & -0.4 & $-11.0 \%$ & 0.23 \\
Scenario 3 & $-6.0 \%$ & $-83.0 \%$ & 0.0 & $2.1 \%$ & 0.79 \\
Scenario 4 & $-5.8 \%$ & $-86.5 \%$ & 0.1 & $1.4 \%$ & 0.67 \\
Scenario 5 & $-12.2 \%$ & $-40.6 \%$ & -0.3 & $-6.0 \%$ & 0.30 \\
Scenario 6 & $-10.7 \%$ & $-40.7 \%$ & -0.2 & $-5.1 \%$ & 0.36 \\
Scenario 9 & $-12.2 \%$ & $-42.7 \%$ & -0.3 & $0.3 \%$ & -0.01 \\
\hline
\end{tabular}

- Scenario 1 presented the highest cost decrease of $15.5 \%$, as well as energy decrease of $10.8 \%$. However, this was at the expense of lower indoor temperature, which was reduced by $0.6{ }^{\circ} \mathrm{C}$ compared to the mean temperature of the reference operation.

- Scenario 3 achieved the highest indicator of load shifting during night time, namely 0.79 . Cost was decreased by $6 \%$, but energy use was moderately increased by $2.1 \%$. The mean indoor temperature was the same as that of the reference operation, but with more fluctuations during the day.

- Scenario 4 achieved the highest decrease in energy use during morning peak hours by $86.5 \%$. Cost was decreased by $5.8 \%$, with only small differences in the total energy use and mean indoor temperature.

- Scenario 9 achieved the highest indicator of load shifting during periods with lower heat production cost, namely 0.52. Cost was decreased by $12.2 \%$, with almost the same energy use as the reference scenario. The mean indoor temperature slightly lower than that of the reference operation and fluctuated within a wider temperature range.

The study was performed across the entire heating season; however, the weather is expected to have significant influence among the various scenarios. Indicatively, Table 3 presents the average performance evaluation and flexibility potential of the selected scenarios during a cold day of the heating season.

Table 3: Average performance and flexibility potential in different scenarios during a cold day

\begin{tabular}{|c|c|c|c|c|c|c|}
\hline \multirow[b]{2}{*}{ Scenarios } & \multicolumn{4}{|c|}{ Difference from reference operation } & \multirow[b]{2}{*}{$\mathbf{F 1}$} & \multirow[b]{2}{*}{$\mathbf{F} 2$} \\
\hline & Cost $[\%]$ & $\begin{array}{l}\text { Energy use in } \\
\text { morning [\%] }\end{array}$ & $\begin{array}{l}\text { Average } \\
\text { temperature }\left[{ }^{\circ} \mathrm{C}\right]\end{array}$ & Total energy [\%] & & \\
\hline Reference & - & - & - & - & 0.03 & -0.77 \\
\hline Scenario 1 & $-4.4 \%$ & $-75.1 \%$ & $-0.5^{\circ} \mathrm{C}$ & $-0.1 \%$ & 0.80 & -0.55 \\
\hline Scenario 2 & $-8.0 \%$ & $-79.5 \%$ & $-0.2^{\circ} \mathrm{C}$ & $-2.9 \%$ & 0.57 & -0.60 \\
\hline Scenario 3 & $28.1 \%$ & $-80.9 \%$ & $0.1^{\circ} \mathrm{C}$ & $36.6 \%$ & 0.88 & -0.51 \\
\hline
\end{tabular}




\begin{tabular}{llllllll}
\hline Scenario 4 & $14.7 \%$ & $-80.9 \%$ & $0.3^{\circ} \mathrm{C}$ & $21.7 \%$ & 0.87 & -0.51 & 0.24 \\
Scenario 5 & $-41.7 \%$ & $-69.7 \%$ & $-0.7{ }^{\circ} \mathrm{C}$ & $-18.2 \%$ & 0.63 & 0.08 & 0.41 \\
Scenario 6 & $-35.7 \%$ & $-72.7 \%$ & $-0.7{ }^{\circ} \mathrm{C}$ & $-9.2 \%$ & 0.05 & 0.82 & $0.0 \%$ \\
Scenario 9 & $-40.4 \%$ & $-79.2 \%$ & $-0.7{ }^{\circ} \mathrm{C}$ & $0.0 \%$ \\
\hline
\end{tabular}

For the scenarios with fixed schedules, during a very cold day the potential for cost reduction was lower and $F_{2}$ was considerably lower than the average of the heating season. Scenarios 3 and 4 that pre-heated the building during the night resulted in higher costs and considerably higher energy use. The scenarios with dynamic response to the cost signal, achieved considerable cost reduction, but at the expense of lower indoor temperatures.

\section{Discussion}

Choosing which of the scenarios to implement is a multifactorial decision. First and foremost, it depends on the services that energy flexible buildings should provide to the energy system. It may be the minimization of energy use during specific hours, the reduction of cost, the alleviation of local congestion problems, or the smoothing of the overall heat load. Furthermore, the aforementioned results may come at the expense of a wider temperature range and/or more fluctuations in the indoor temperature during the day. The level of acceptance of thermal comfort changes may as well affect the choice of the strategy to be implemented. In some cases higher total energy was observed, but this may be considered acceptable, as it is still costs less and it is probably less carbon intensive.

The signals used in this study have a significant influence on the obtained results. Different signals can be used to trigger the flexibility of a building, such as $\mathrm{CO}_{2}$ emissions from heat production or the actual heat prices. To date, in Denmark the heat price paid by the customers is constant across the year and fixed by individual contracts, so there is no incentive for the individual customers to participate in similar strategies and decrease their energy use during peak hours. However, dynamic heat pricing is under research and it was the scope of this work to identify if there is potential for this type of building to be operated flexibly. Further work towards demand response in buildings connected to DH is needed and it will heavily depend on the specific DH market structure. In addition, scenarios with increased use of electricity for heating with increased deployment of heat pumps and electrical boilers can be considered. In such cases, the wind power production will be an appropriate signal to use to investigate different regimes and the interaction with the electric grid e.g., "wind power peak" and "no wind". One can envision that in cases with a significant share of wind power integrated in the generation systems of $\mathrm{DH}$, the form of the marginal costs curve would change as well. By using different signals, the control strategy and the quantification of the results and metrics may be different, but the dynamic thermal response of the building, which is presented in this paper, is anticipated to be similar.

In this study, the approach that was followed was an indirect load control assuming that all occupants of the building participated in the control strategy. Reality would probably be different, as in the indirect load control occupants would 
have the choice not to participate, i.e. adjust their set-points. This would result in effects of a different magnitude than those simulated in this study. The percentage of occupants who participate in the control scheme is an important parameter when planning to implement flexibility strategies in residential buildings. Another important parameter, especially if using thermal mass as storage to facilitate flexibility, is the thermal comfort acceptability range of occupants which can vary significantly, as it was also pointed out by [24], who performed a field study on a sample of 28 homes in England deploying heating system demand-shifting with a focus on occupants' thermal comfort. In the present study, this may be more critical since many of the proposed scenarios suggest opposite set-points to typical night set-back schedules. Nevertheless, for occupants to be willing to accept the changes on thermal comfort if their buildings should be operated flexibly, they need to be properly informed and motivated. Since monetary incentives are those, which mostly attract attention and motivate participation [24], [42], it should be further investigated how the benefits achieved for the system at the production side could be reflected to the prices that the occupants pay.

In addition to their decision whether to participate in flexibility strategies or not, occupants of residential buildings have an impact on the flexibility potential with their behavior, in terms of occupancy patterns and thermal comfort preferences. The schedule and intensity of the occupants' patterns affect significantly the internal gains in the building, especially in low-energy buildings, and thus the demand that the heating system should cover. Furthermore, the thermal comfort preference, i.e. temperature set-point, affects significantly the heating demand; thereby, the potential for flexible operation. In this study, a deterministic occupancy pattern from standards was used and a reference set-point of $22{ }^{\circ} \mathrm{C}$ constantly, which is a typical desired indoor temperature in Danish households during the heating season. However, those may be different in reality, thus more representative or stochastic models for occupants' behavior would improve the realism of the obtained results [55-58].

An important parameter to be further investigated is the effect of the implementation of those scenarios on the district or city level. The results can be further extended with aggregation studies creating a category of such buildings that can be added to the portfolio of solutions for storage in the energy system. In the scenarios implemented, new peak loads were created in the building, at the beginning of low production cost or low system load periods. In order to avoid disturbances in the system, a smoother ramp in the heating set-point control in the building could be set and/or the heat supplier could send signals which are slightly shifted in time to different categories of consumers. The specific design of the district heating system in the area, as well as hydraulic constraints should be considered.

\section{Conclusions}

This paper modelled the potential for a low-energy residential building to be operated flexibly, according to the needs 
of the local district heating system for peak load shaving and cost reduction, to support extending the thermal storage potential of the DH system, which consequently facilitates the flexibility of the energy system. The structural thermal mass was used as storage medium to facilitate the flexible operation of the building, which was achieved by modulating the indoor air temperature set-point. Different control strategies were implemented, determined based on the marginal heat production cost and the heat load of Greater Copenhagen. The different control signals, i.e. fixed schedules and dynamic, triggered an increase or decrease of the air temperature set-point, in order to charge or discharge the thermal mass. Based on the average daily profiles of heat load and marginal heat production cost, it was, on average, favorable for the system to utilize heat during night time, as the total heat load in the area is low and base load boilers are normally used. Thus, heat costs less to be produced, and it is less carbon-intensive.

With all scenarios implemented, a significant energy reduction in the morning peak load hours was reached, between $40 \%$ and $87 \%$, for this type of building. There were also reduced costs by up to $15 \%$ during a heating season, except scenario 3 and 4 on the cold winter day. This is due to higher heat loss from the building on the extremely cold day. In most scenarios, the total energy use during a heating season decreased by up to $11 \%$, but in a few scenarios the total energy use increased by up to $2 \%$. Higher energy use may be considered acceptable, as it costs less to be produced and can be beneficial for the environment as it less carbon-intensive. With the implemented strategies, new peaks in the heating load of the building were created. However, since they occurred during low load hours and were within the installed capacity of the building heating system, they are not considered as an impediment to the proposed strategies. The thermal environment was changed, as a wider temperature range and/or more frequent fluctuations in the indoor temperature occurred.

This study showed that there is potential in low-energy residential buildings to be operated flexibly achieving peak load shaving and cost reduction in the district heating system. The choice of the best performing scenario is not straightforward, as it would depend on the services that the building is to offer to the district heating system. Some scenarios indicated higher potential for cost reduction (dynamic temperature set-points), while other achieved greater load shifting (fixed schedules for temperature set-points). The magnitude of the benefits that can be achieved depends on whether the changes in the energy use are acceptable and on the level of thermal comfort required by the occupants. To implement the outcomes of this study higher morning heat prices could be recommended. Intelligent control of heating systems is also recommended to be part of future heating systems to implement price responsive controls. Intelligent control is especially important when the control signal is dynamic, that could be real-time wind power production or real time $\mathrm{CO}_{2}$ emission in heat production. Further investigations are to be performed in this research topic and real-life demonstrations are taking place within the EnergyLab Nordhavn project. 


\section{Acknowledgements}

This research is part of the Danish research project "EnergyLab Nordhavn - New Urban Energy Infrastructures" supported by the Danish Energy Technology Development and Demonstration Programme (EUDP). Project number: 64014-0555. This work is also part of research activities of IEA-EBC Annex 67 (International Energy Agency - Energy in Buildings and Communities programme) Energy Flexible Buildings. Thibault Péan is funded by the H2020 programme under the MSCA INCITE ITN, GA 675318. The authors would like to thank the utility company of Copenhagen, HOFOR A/S, for providing the data about the district heating system and Kristian Honoré (HOFOR A/S) for proofreading the manuscript.

\section{Declaration of competing interests}

we wish to confirm that there are no known conflicts of interest associated with this publication and there has been no significant financial support for this work that could have influenced its outcome.

We confirm that the manuscript has been read and approved by all named authors and that there are no other persons who satisfied the criteria for authorship but are not listed. We further confirm that the order of authors listed in the manuscript has been approved by all of us.

We confirm that we have given due consideration to the protection of intellectual property associated with this work and that there are no impediments to publication, including the timing of publication, with respect to intellectual property. In so doing we confirm that we have followed the regulations of our institutions concerning intellectual property.

We understand that the Corresponding Author is the sole contact for the Editorial process (including Editorial Manager and direct communications with the office). She is responsible for communicating with the other authors about progress, submissions of revisions and final approval of proofs. We confirm that we have provided a current, correct email address which is accessible by the Corresponding Author.

\section{References}

[1] A.H. Mohsenian-Rad, V.W.S. Wong, J. Jatskevich, R. Schober, A. Leon-Garcia, Autonomous demand-side management based on game-theoretic energy consumption scheduling for the future smart grid, IEEE Trans. Smart Grid. 1 (2010) 320-331. doi:10.1109/TSG.2010.2089069.

[2] H. Lund, A.N. Andersen, P.A. Østergaard, B.V. Mathiesen, D. Connolly, From electricity smart grids to smart energy systems - A market operation based approach and understanding, Energy. 42 (2012) 96-102. doi:10.1016/j.energy.2012.04.003. 
[3] H. Lund, P.A. Østergaard, D. Connolly, I. Ridjan, B.V. Mathiesen, F. Hvelplund, J.Z. Thellufsen, P. Sorknæs, Energy Storage and Smart Energy Systems, Int. J. Sustain. Energy Plan. Manag. 11 (2016) 3-14. doi:10.5278/ijsepm.2016.11.2.

[4] M. Münster, P.E. Morthorst, H. V. Larsen, L. Bregnbæk, J. Werling, H.H. Lindboe, H. Ravn, The role of district heating in the future Danish energy system, Energy. 48 (2012) 47-55. doi:10.1016/j.energy.2012.06.011.

T. Nuytten, B. Claessens, K. Paredis, J. Van Bael, D. Six, Flexibility of a combined heat and power system with thermal energy storage for district heating, Appl. Energy. 104 (2013) 583-591.

doi:10.1016/j.apenergy.2012.11.029.

[6] H. Cai, C. Ziras, S. You, R. Li, K. Honoré, H.W. Bindner, Demand side management in urban district heating networks, Appl. Energy. 230 (2018) 506-518. doi:10.1016/j.apenergy.2018.08.105.

[7] J. Heier, C. Bales, V. Martin, Combining thermal energy storage with buildings - a review, Renew. Sustain. Energy Rev. 42 (2015) 1305-1325. doi:10.1016/j.rser.2014.11.031.

[8] A. Arteconi, N.J. Hewitt, F. Polonara, State of the art of thermal storage for demand-side management, Appl. Energy. 93 (2012) 371-389. doi:10.1016/j.apenergy.2011.12.045.

[9] H. Johra, P. Heiselberg, Influence of internal thermal mass on the indoor thermal dynamics and integration of phase change materials in furniture for building energy storage: A review, Renew. Sustain. Energy Rev. 69 (2017) 19-32. doi:10.1016/j.rser.2016.11.145.

[10] N.J. Hewitt, Heat pumps and energy storage - The challenges of implementation, Appl. Energy. 89 (2012) $37-44$. doi:10.1016/j.apenergy.2010.12.028.

[11] G. Reynders, T. Nuytten, D. Saelens, Potential of structural thermal mass for demand-side management in dwellings, Build. Environ. 64 (2013) 187-199. doi:10.1016/j.buildenv.2013.03.010.

[12] D. Patteeuw, G. Reynders, K. Bruninx, C. Protopapadaki, E. Delarue, W. D’haeseleer, D. Saelens, L. Helsen, CO2-abatement cost of residential heat pumps with active demand response: Demand- and supply-side effects, Appl. Energy. 156 (2015) 490-501. doi:10.1016/j.apenergy.2015.07.038.

[13] L. Schibuola, M. Scarpa, C. Tambani, Demand response management by means of heat pumps controlled via real time pricing, Energy Build. 90 (2015) 15-28. doi:10.1016/j.enbuild.2014.12.047.

[14] T.Q. Péan, J. Salom, J. Ortiz, Potential and optimization of a price-based control strategy for improving energy flexibility in Mediterranean buildings, Energy Procedia. 122 (2017) 463-468. doi:10.1016/j.egypro.2017.07.292.

[15] E. Nyholm, S. Puranik, É. Mata, M. Odenberger, F. Johnsson, Demand response potential of electrical space heating in Swedish single-family dwellings, Build. Environ. 96 (2016) 270-282. 
doi:10.1016/j.buildenv.2015.11.019.

[16] M. Åberg, L. Fälting, A. Forssell, Is Swedish district heating operating on an integrated market? - Differences in pricing, price convergence, and marketing strategy between public and private district heating companies, Energy Policy. 90 (2016) 222-232. doi:10.1016/j.enpol.2015.12.030.

[17] H. Li, Q. Sun, Q. Zhang, F. Wallin, A review of the pricing mechanisms for district heating systems, Renew. Sustain. Energy Rev. 42 (2015) 56-65. doi:10.1016/j.rser.2014.10.003.

[18] J. Song, F. Wallin, H. Li, District heating cost fluctuation caused by price model shift, Appl. Energy. 194 (2017) 715-724. doi:10.1016/j.apenergy.2016.09.073.

[19] F. Wernstedt, P. Davidsson, C. Johansson, Demand side management in district heating systems, Proc. 6th Int. Jt. Conf. Auton. Agents Multiagent Syst. - AAMAS '07. 5 (2007) 1. doi:10.1145/1329125.1329454.

[20] C. Johansson, F. Wernstedt, P. Davidsson, Deployment of Agent Based Load Control in District Heating Systems, First Int. Work. Agent Technol. Energy Syst. (ATES 2010). (2010) 75-82.

[21] D. Basciotti, R.-R. Schmidt, Demand side management in district heating networks: Simulation Case Study on Load Shifting, Euro Heat Power. 10 (2013) 43-46.

[22] D.F. Dominković, P. Gianniou, M. Münster, A. Heller, C. Rode, Utilizing thermal building mass for storage in district heating systems: Combined building level simulations and system level optimization, Energy. 153 (2018) 949-966. doi:10.1016/j.energy.2018.04.093.

[23] J. Kensby, A. Trüschel, J.-O. Dalenbäck, Potential of residential buildings as thermal energy storage in district heating systems - Results from a pilot test, Appl. Energy. 137 (2015) 773-781. doi:10.1016/j.apenergy.2014.07.026.

[24] T. Sweetnam, C. Spataru, M. Barrett, E. Carter, Domestic demand-side response on district heating networks, Build. Res. Inf. 0 (2018) 1-14. doi:10.1080/09613218.2018.1426314.

[25] S. Kärkkäinen, K. Sipilä, L. Pirvola, J. Esterinen, E. Eriksson, S. Soikkeli, Demand side management of the district heating systems, (2003) 95. http://www.vtt.fi/inf/pdf/.

[26] J. Van Deventer, J. Gustafsson, J. Delsing, Controlling district heating load through prices, 2011 IEEE Int. Syst. Conf. SysCon 2011 - Proc. (2011) 461-465. doi:10.1109/SYSCON.2011.5929104.

[27] Danish Energy Agency, Regulation and planning of district heating in Denmark, (2015) 27. http://www.ens.dk/sites/ens.dk/files/climate-co2/GlobalCooperation/Publications/Publications/regulation_and_planning_of_district_heating_in_denmark.pdf.

[28] Energistyrelsen, Energistatistik 2016, Data, tabeller, statistikker og kort, Copenhagen, 2017. 
https://ens.dk/sites/ens.dk/files/Statistik/estat2016.pdf.

[29] Danish Energy Agency, The Danish Energy Model, 2017.

https://ens.dk/sites/ens.dk/files/contents/material/file/the_danish_energy_model.pdf.

[30] Varmelast.dk, (2018). http://varmelast.dk/en.

[31] Danish Transport and Construction Agency, Danish Building Regulations 2015, 2015.

http://historisk.bygningsreglementet.dk/file/591081/br15_english.pdf.

[32] Ministry of Transport Building and Housing, Executive order on building regulations 2018 (BR18), (2018). http://bygningsreglementet.dk/ /media/Br/BR-

English/BR18_Executive_order_on_building_regulations_2018.pdf.

[33] Danish Energy Agency, Danish Board of District Heating, State of Green, District heating - Danish experiences, 2015. doi:10.1109/ICEMI.2013.6743020.

[34] K. Foteinaki, R. Li, A. Heller, C. Rode, Heating system energy flexibility of low-energy residential buildings, Energy Build. 180 (2018) 95-108. doi:10.1016/j.enbuild.2018.09.030.

[35] T.S. Larsen, R.L. Jensen, O. Daniels, Målinger og Analyse af Indeklima og Energiforbrug i Komforthusene, Department of Civil Engineering, Aalborg University, 2012.

http://vbn.aau.dk/files/60642088/Komforthusene_M_linger_og_Analyse_af_Indeklima_og_Energiforbrug_i_8_P assivhuse_2008_2011.pdf.

[36] EN/DS 15251, Indoor environmental input parameters for design and assessment of energy performance of buildings addressing indoor air quality, thermal environment, lighting and acoustics, Dansk Stand. (2007) 54.

[37] Q. Sun, H. Li, F. Wallin, Q. Zhang, Marginal costs for district heating, Energy Procedia. 104 (2016) 323-328. doi:10.1016/j.egypro.2016.12.055.

[38] HOFOR A/S, Greater Copenhagen Utility, Https://Www.Hofor.Dk. (2018).

[39] J. Sjödin, D. Henning, Calculating the marginal costs of a district-heating utility, Appl. Energy. 78 (2004) 1-18. doi:10.1016/S0306-2619(03)00120-X.

[40] K. Difs, L. Trygg, Pricing district heating by marginal cost, Energy Policy. 37 (2009) 606-616. doi:10.1016/j.enpol.2008.10.003.

[41] S. Karjalainen, Thermal comfort and use of thermostats in Finnish homes and offices, Build. Environ. 44 (2009) 1237-1245. doi:10.1016/j.buildenv.2008.09.002.

[42] R. Li, G. Dane, C. Finck, W. Zeiler, Are building users prepared for energy flexible buildings? —A large-scale survey in the Netherlands, Appl. Energy. 203 (2017) 623-634. doi:10.1016/j.apenergy.2017.06.067. 
[43] C. Evens, S. Kärkkäinen, Pricing models and mechanisms for the promotion of demand side integration, (2009) 58. http://www.ece.hut.fi/enete/Pricong_models.pdf.

[44] C. Sandersen, K. Honoré, District heating flexibility - short term heat storage in buildings, EnergyLab Nordhavn Deliverables, 2018.

http://www.energylabnordhavn.com/uploads/3/9/5/5/39555879/d5.2c_short_term_heat_storage_in_buildings.pdf.

[45] J. Le Dréau, P. Heiselberg, Energy flexibility of residential buildings using short term heat storage in the thermal mass, Energy. 111 (2016) 991-1002. doi:10.1016/j.energy.2016.05.076.

[46] S. Aggerholm, K. Grau, Bygningers energibehov - Beregningsvejledning - SBi-anvisning 213, Aalborg, 2014.

[47] TABULA WebTool, (2017). http://webtool.building-typology.eu (accessed October 11, 2017).

[48] EQUA Simulation AB, IDA Indoor Climate and Energy - A new generation building performance simulation software, IDA Indoor Clim. Energy. (2018). https://www.equa.se/en/ida-ice.

[49] EQUA Simulation AB, Validation of IDA Indoor Climate and Energy 4 . 0 with respect to CEN Standards EN 15255-2007 and EN 15265-2007, Solna, Sweden, 2010.

[50] EQUA Simulation AB, Validation of IDA Indoor Climate and Energy 4.0 build 4 with respect to ANSI/ASHRAE Standard 140-2004, Solna, Sweden, 2010.

[51] S. Kropf, G. Zweifel, Validation of the Building Simulation Program IDA-ICE According to CEN 13791 , Thermal Performance of Buildings - Calculation of Internal Temperatures of a Room in Summer Without Mechanical Cooling - General Criteria and Validation Procedures “, 2001.

[52] P. Loutzenhiser, H. Manz, G. Maxwell, International Energy Agency’s SHC Task 34 - ECBCS Annex 43 Project C: Empirical Validations of Shading / Daylighting / Load I nteractions in Building Interactions Energy Simulation Tools, 2007.

[53] Technical University of Denmark - Department of Civil Engineering, DTU Climate Station-Climate Data, (2018). http://climatestationdata.byg.dtu.dk.

[54] DS/EN ISO 13790, Energy performance of buildings - Calculation of energy use for space heating and cooling, Dansk Stand. (2008) 178.

[55] A. Wang, R. Li, S. You, Development of a data driven approach to explore the energy flexibility potential of building clusters, Appl. Energy. (2018). doi:10.1016/j.apenergy.2018.09.187.

[56] R. Li, F. Wei, Y. Zhao, W. Zeiler, Implementing Occupant Behaviour in the Simulation of Building Energy Performance and Energy Flexibility: Development of Co-Simulation Framework and Case Study, Proc. Build. Simul. 2017. (2017) 1339-1346. 
[57] J. Widén, A. Molin, K. Ellegård, Models of domestic occupancy, activities and energy use based on time-use data: Deterministic and stochastic approaches with application to various building-related simulations, J. Build. Perform. Simul. 5 (2012) 27-44. doi:10.1080/19401493.2010.532569.

[58] J. Widén, M. Lundh, I. Vassileva, E. Dahlquist, K. Ellegård, E. Wäckelgård, Constructing load profiles for household electricity and hot water from time-use data-Modelling approach and validation, Energy Build. 41 (2009) 753-768. doi:10.1016/j.enbuild.2009.02.013. 